Classification

Physics Abstracts

$61.16 \mathrm{~d}-74.70$

\title{
H.R.E.M study of the cuprate $\mathrm{Sr}_{2} \mathrm{NdCu}_{2} \mathrm{O}_{5.76}$
}

\author{
Maryvonne Hervieu, Vincent Caignaert, Claude Michel, Richard Retoux \\ and Bernard Raveau
}

Laboratoire de cristallographie et Sciences des Matériaux ISMRA, Bd du Maréchal Juin, 14032 Caen

Cedex, France

(Received March 26, 1990; accepted June 05, 1990)

\begin{abstract}
Résumé. - L'étude par microscopie électronique haute résolution de l'oxyde $\mathrm{Sr}_{2} \mathrm{Nd} \mathrm{Cu}_{2} \mathrm{O}_{5.76}$, récemment caractérisé, a été réalisée. La structure de cet oxyde est construite par intercroissance de couches de type $\mathrm{NaCl}$ et pérovskite. La distribution originale des lacunes oxygène, qui a conduit à deux modèles structuraux extrêmes, est discutée. L'étude microstructurale montre que, parmi les phénomènes de non stoéchiométrie observés, deux apparaissent comme très importants : les défauts d'intercroissance $\left(n^{\prime}=3\right)$ et l'interconnexion de couches qui entraîne la formation de parois d'antiphase.
\end{abstract}

\begin{abstract}
The HREM study of the new oxide $\mathrm{Sr}_{2} \mathrm{Nd} \mathrm{Cu}_{2} \mathrm{O}_{5.76}$, whose structure is built up from the intergrowth of rock-salt and perovskite layers, is reported. The original distribution of the oxygen vacancies in the perovskite slabs, which led to two extrem structural models, is discussed. The microstructural study shows that, among the nonstoichiometric phenomena observed in the crystal, two appear common : intergrowth defects $\left(n^{\prime}=3\right)$ and interconnections of layers which involve antiphase boundaries.
\end{abstract}

\section{Introduction.}

The recent investigations of high $T_{\mathrm{c}}$ superconductors have shown that two factors are of capital importance for the appearance of superconductivity in copper oxides : mixed valence of copper and low dimensionality of the structure. One can indeed describe all those superconducting phases by the formula $\left(\mathrm{ACuO}_{3-x}\right)_{m}\left(\mathrm{~A}^{\prime} \mathrm{O}\right)_{n}$, corresponding to various intergrowths of oxygen deficient perovskite layers and rock salt-type layers [1] . However, the origin of superconductivity is so far not clear and, especially, if we consider the oxides $\mathrm{La}_{2-x} \mathrm{~A}_{1-x} \mathrm{Cu}_{2} \mathrm{O}_{6}(\mathrm{~A}=\mathrm{Ca}, \mathrm{Sr})$, the $[2,1]$ i.e. $[m=2, n=1]$ member for which no sign of superconductivity was detected $[3,4]$. Thus it appears as fundamental to study the $[2,1]$ oxides, even if they do not superconduct. Recently, a new nonsuperconducting [2,1] oxide, $\mathrm{Sr}_{2} \mathrm{NdCu}_{2} \mathrm{O}_{6-x}$ [5] was isolated. The study of its structure by $\mathrm{X}$ ray and neutron diffraction showed that this phase differs from the classical $[2,1] \mathrm{La}_{2} \mathrm{SrCu}_{2} \mathrm{O}_{6}$-type oxide by the nature of the distribution of the oxygen vacancies in the perovskite slabs. Nevertheless, one can obtain by those methods only a mean structure, owing to the various possible 
orderings of oxygen in the crystals. Thus, the present paper deals with the HREM study of the oxide $\mathrm{Sr}_{2} \mathrm{NdCu}_{2} \mathrm{O}_{6-x}$, synthesized in air.

\section{Experimental.}

Samples for HREM investigation were prepared by heating mixtures of strontium carbonate, neodymium and copper oxides at temperatures ranging from $1000^{\circ} \mathrm{C}$ to $1100^{\circ} \mathrm{C}$ according to the experimental method described previously [5]. A pure orthorhombic phase was isolated with the following parameters $a=3.770 \AA, b=11.438 \AA c=20.094 \AA$. The E.D. study performed with a JEOL $120 \mathrm{CX}$ electron microscope attested of the homogeneity of the samples and of the reflection conditions, $h k l: h+k+l=2 n$. The chemical analysis, performed by iodometric titration gave evidence of the formula $\mathrm{Sr}_{2} \mathrm{NdCu}_{2} \mathrm{O}_{5.7}$ in agreement with the neutron diffraction refinements $\left(\mathrm{Sr}_{2} \mathrm{NdCu}_{2} \mathrm{O}_{5.76}\right)[5]$.

Specimens for electron microscopy were prepared by suspending in alcohol very thin crystals (obtained from a thorough grinding of the sample); few droplets of the suspension were put on a carbon coated holey film.

The high resolution electron microscopy study was performed with a JEOL200 CX electron microscope fitted with a double-tilt goniometer and an objective lens whose spherical aberration constant is $0.8 \mathrm{~mm}$. Image simulations were calculated following the multislice method; structural data were based on the results of the neutron powder results [5]. Calculation parameters were : high voltage $V=200 \mathrm{kV}, C_{\mathrm{s}}=0.8 \mathrm{~mm}$, semi angle of beam convergence $\alpha / 2=0.8 \mathrm{mrad}$, half focus spread $\Delta / 2=7,5 \mathrm{~nm}$. Images were calculated for different thicknesses of the crystals : $22 \AA, 30 \AA, 38 \AA$ and $49 \AA$ and different focus values.

\section{Results and discussion.}

\section{Structure and contrast understanding :}

The structure of this oxide(Fig. 1a) obtained from the neutron diffraction data [5] shows that it can be described as an intergrowth of single rock salt-type layers $\left[\mathrm{Sr}_{0.77} \mathrm{Nd}_{0.23} \mathrm{O}\right]_{\infty}$ with oxygen deficient double rock salt-type layers $\left[\mathrm{Sr}_{1.23} \mathrm{Nd}_{0.77} \mathrm{Cu}_{2} \mathrm{O}_{4.8}\right]_{\infty}$. The distribution of the oxygen vacancies in the perovskite layer is original with respect to other layered cuprates involving double copper slabs. Firstly, one observes $\mathrm{CuO}_{5}$ pyramids whose basal planes are parallel to c, i.e. orthogonal to the layers. Second, the $O_{\left(8^{\prime}\right)}$ and $O_{(4)}$ sites which were empty and fully occupied, respectively, in other layered cuprates are partly occupied in this new oxide. A full occupancy of $\mathrm{O}(4)$ with $\tau_{\left(\mathrm{O}^{\prime}\right)}=0$ would imply a pyramidal coordination for $\mathrm{Cu}(1)$, the basal plane of the pyramid being parallel to the layers as shown in figure 1c. When $O(4)$ site is empty and $O\left(8^{\prime}\right)$ occupied, $\mathrm{Cu}(1)$ exhibits a distorted square planar coordination, as shown in figure $1 \mathrm{~b}$; such a structure can be obtained by annealing $\mathrm{Sr}_{2} \mathrm{NdCu}_{2} \mathrm{O}_{5.76}$ under inert atmosphere [7] . The occupancy of these anionic sites in $\mathrm{Sr}_{2} \mathrm{NdCu}_{2} \mathrm{O}_{5.76}$ can be statistic as shown in figure 1a, but can also be the result of the coexistence in the same crystal of two sorts of microdomains corresponding to two extrem structural models with formula $\mathrm{Sr}_{2} \mathrm{NdCu}_{2} \mathrm{O}_{5.66}$ (Fig. 1b) and $\mathrm{Sr}_{2} \mathrm{NdCu}_{2} \mathrm{O}_{6}$ (Fig. 1c). The first one (Fig. 1b) can be described from the intergrowth of "123" type ribbons with rock salt layers [7] , whereas the second (Fig. 1c) is characterized by hexagonal tunnels similar to those encountered in $\mathrm{BaLa}_{4} \mathrm{Cu}_{5} \mathrm{O}_{13}$ [6] . The HREM observation of this oxide along [100] and [010] should allow the existence of such different domains to be detected under definite conditions.

Along [100], the superstructure $b \approx 3 \times a_{p}$ due to the oxygen vacancies ordering, leads to a striking variation of the contrast. The most typical contrast corresponds to a honeycomb like 

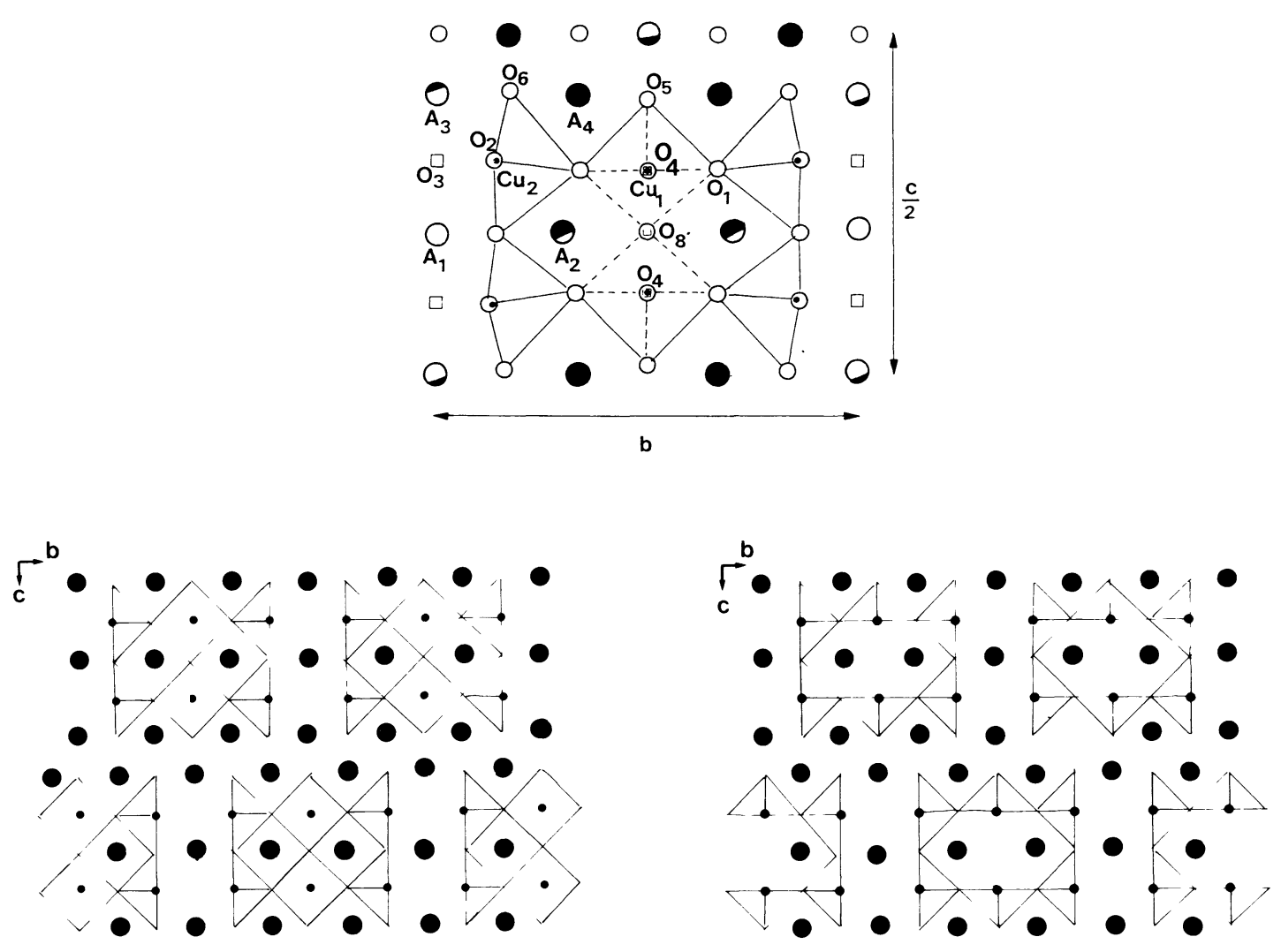

Fig. 1. $-\mathrm{Sr}_{2} \mathrm{NdCu}_{2} \mathrm{O}_{5.76}$ a) Structure from the neutron diffraction data projected along [100]. (Model I) : $\mathrm{O}(4)$ and $\mathrm{O}\left(8^{\prime}\right)$ sites are partly occupied. b) First extrem model, $\mathrm{Sr}_{2} \mathrm{NdCu}_{2} \mathrm{O}_{5}$.66 built up from $\mathrm{CuO}_{4}$ groups and $\mathrm{CuO}_{5}$ pyramids. (Model II) : $\mathrm{O}$ (4) site is empty. c) Second extrem model, $\mathrm{Sr}_{2} \mathrm{NdCu}_{2} \mathrm{O}_{6}$ built up from $\mathrm{CuO}_{5}$ pyramids. (Model III) : $\mathrm{O}(4)$ site is fully occupied.

image (Fig. 2). Nevertheless the contrast is highly sensitive to the thickness of the crystal and to very slight misorientations. An example of this very rapid variation of the contrast with thickness is shown in figure 3. Images calculated for the structural parameters refined from the neutron study and for a crystal thickness close to $30 \AA$ are shown in figure 4 ; some typical experimental images are compared with the calculated ones in figure 5. From these images, it is clear that the honeycomb like contrast results from both cationic and anionic sublattices as shown from focus values ranging from -50 to $-450 \AA$.

As observed in previous studies of oxygen deficient perovskites, the contrast is scarcely disturbed by a variation of the oxygen content in one site, owing to its weak scattering factor ; however, strong variations of the contrast can be observed when the existence of an oxygen vacancy involves a strong displacement of cations. The existence of two different coordinations for $\mathrm{Cu}_{(1)}$, implied by the partial occupancy factors of $O_{(4)}$ and $O_{\left(8^{\prime}\right)}$, leads of course to discuss the distribution of these oxygens in the matrix. Two hypotheses can be considered :

(i) These oxygens are distributed at random on the $\mathrm{O}_{(4)}$ and $O_{\left(8^{\prime}\right)}$ sites in the crystal, as shown in figure 1a (model I).

(ii) There is local orderings of these $\mathrm{O}_{\left(8^{\prime}\right)}$ and $\mathrm{O}_{(4)}$ oxygens, leading to the coexistence of 


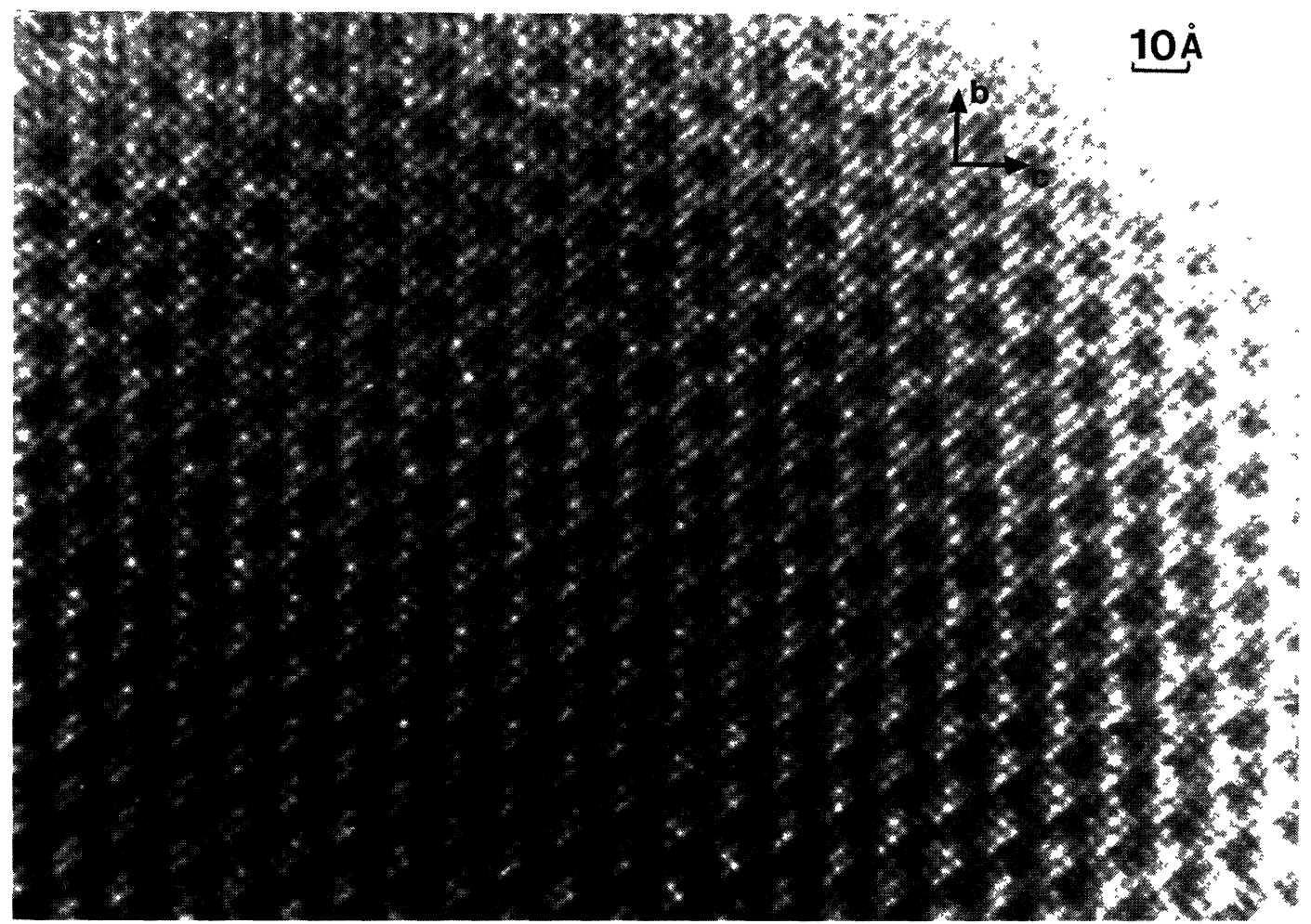

Fig. 2. - typical [100] image of the honeycomb - like contrast.

more or less large domains of the oxides $\mathrm{Sr}_{2} \mathrm{NdCu}_{2} \mathrm{O}_{6.0}$ (model III, Fig. 1c) and $\mathrm{Sr}_{2} \mathrm{NdCu}_{2} \mathrm{O}_{5.66}$ (model II, Fig. 1b) in the same matrix.

The neutron diffraction results are in favour of the first hypothesis since the rather low values of $B$ parameters [5], especially of copper sites, allow splitted positions resulting from two different cationic arrangements to be ruled out and then an homogeneous distribution of the oxygens over $O(4)$ and $O(8)$ sites to be expected.

In order to check this hypothesis, HREM images were calculated for models II and III, corresponding to the second hypothesis. The only differences between the two starting models for calculations were based on the occupancy factors of the $\mathrm{O}_{(4)}$ sites and $\mathrm{O}_{\left(8^{\prime}\right)}$ sites, i.e. $\tau \mathrm{O}_{(4)}=1$ and $\tau^{\prime} \mathrm{O}_{\left(8^{\prime}\right)}=0$ for model III, and $\tau \mathrm{O}_{(4)}=0$ and $\tau \mathrm{O}_{\left(8^{\prime}\right)}=0.5$ splitting of the $\mathrm{O}$ site resulting from the neutron diffraction data, for model (II). In the latter model two different calculations were performed : the first one corresponding to a statistical distribution of the oxygen atoms over the splitted $\mathrm{O}_{\left(8^{\prime}\right)}$ sites $(\tau=0.5)$, and the second one to a full occupancy $(\tau=1)$ of one splitted $\mathrm{O}_{\left(8^{\prime}\right)}$ site out of two, the second adjacent site being empty, in order to enhance the contrast along [010].

These calculations show that, no significant differences can be observed when we only change these two occupancies of the anionic sites and keep unchanged the network, in agreement with our hypothesis. The significant evolution of the cell parameters with the oxygen content [7], especially the $b / a$ ratio which decreases from 3.06 to 3.01 when the oxygen content increases from $\mathrm{O}_{5.66}$ to $\mathrm{O}_{5.8}$, suggests that single crystals of model III, if the phase exists, would impose different cationic positions, which then would imply a significant difference in the contrast. The few local variations 


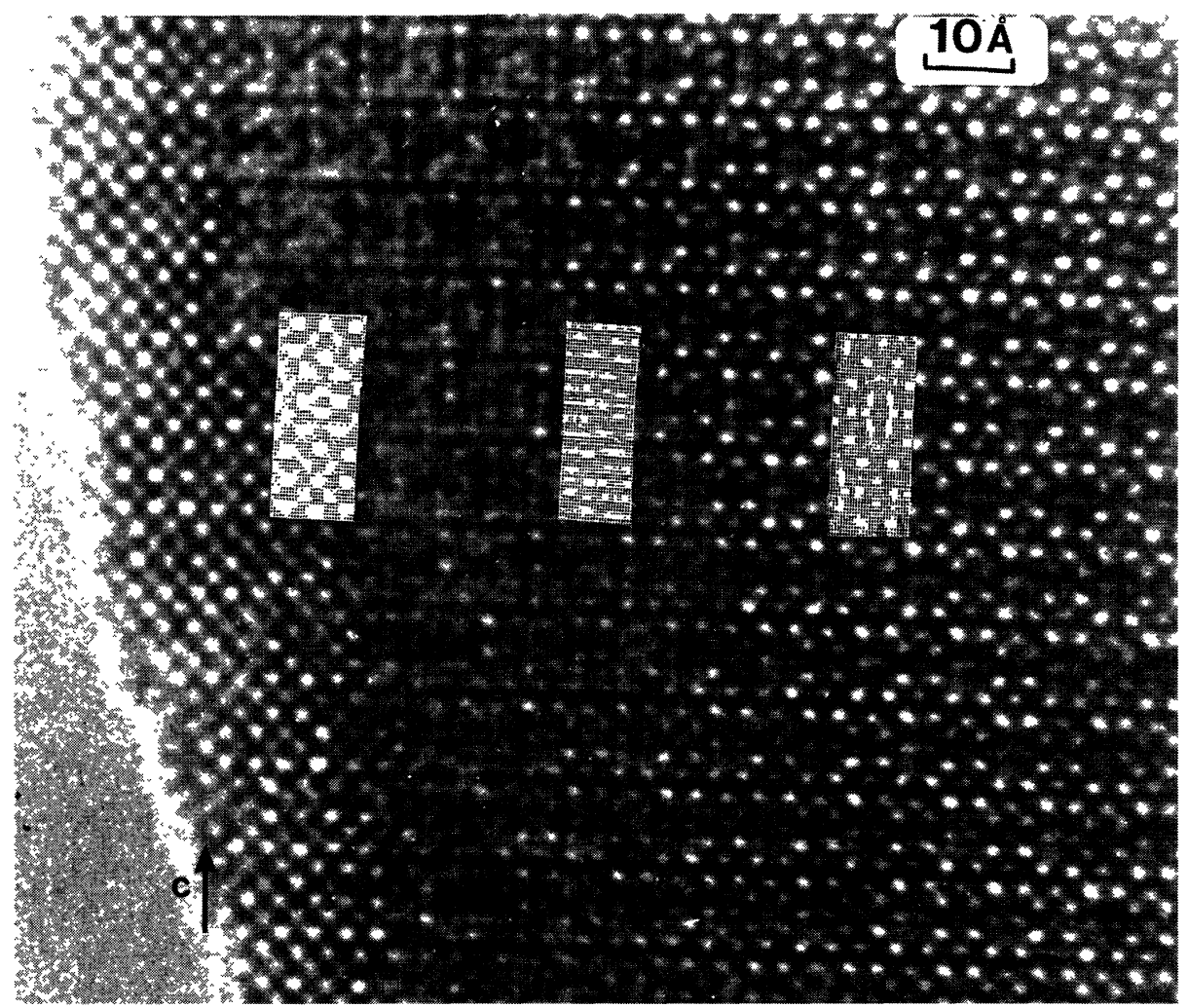

Fig. 3. - example of the rapid variation of contrast with thickness in [100] images. The focus value is close to $-800 \AA$. The images were calculated from neutron diffraction data (see text).

of the contrast which were indeed observed in the crystals were in fact only correlated to the high sensitivity of the contrast to parameters such as thickness and small deviations from a perfect orientation. Thus we consider that N.D. results and HREM observations are in favour of an aleatory distribution of the $\mathrm{Cu}_{(1)} \mathrm{O}_{5}$ pyramids and $\mathrm{Cu}_{(1)} \mathrm{O}_{4}$ groups in the perovskite slabs.

\section{Extended defects and boundaries.}

The striking feature of this phase deals with the great regularity of the superstructure. This is confirmed by the [001] and [010] HREM images (Fig. 6a, 7). The [001] images exhibits indeed a regular network of white dots, spaced of $2.8 \AA$, with a modulation of the contrast along $b$, in agreement with the calculated images (Fig. 6b). In the same way, the [010] images of most of the crystals (Fig. 7) give evidence of the regular intergrowth of the single rock salt-type layers with double perouskite layers. In this latter image, positions of the oxygen and vacancies are highlighted whereas the cationic positions appears as black spots (focus value $\sim-350 \AA$, crystal thickness $\sim 30.5 \AA$ ). A quite uniform contrast is observed as well on the cationic network as on the anionic one, in agreement with the potential projection. The partial through focus series, calculated for a crystal thickness close to $30 \AA$ is shown in figure 8 ; the experimental contrasts fit well with these simulated images. 

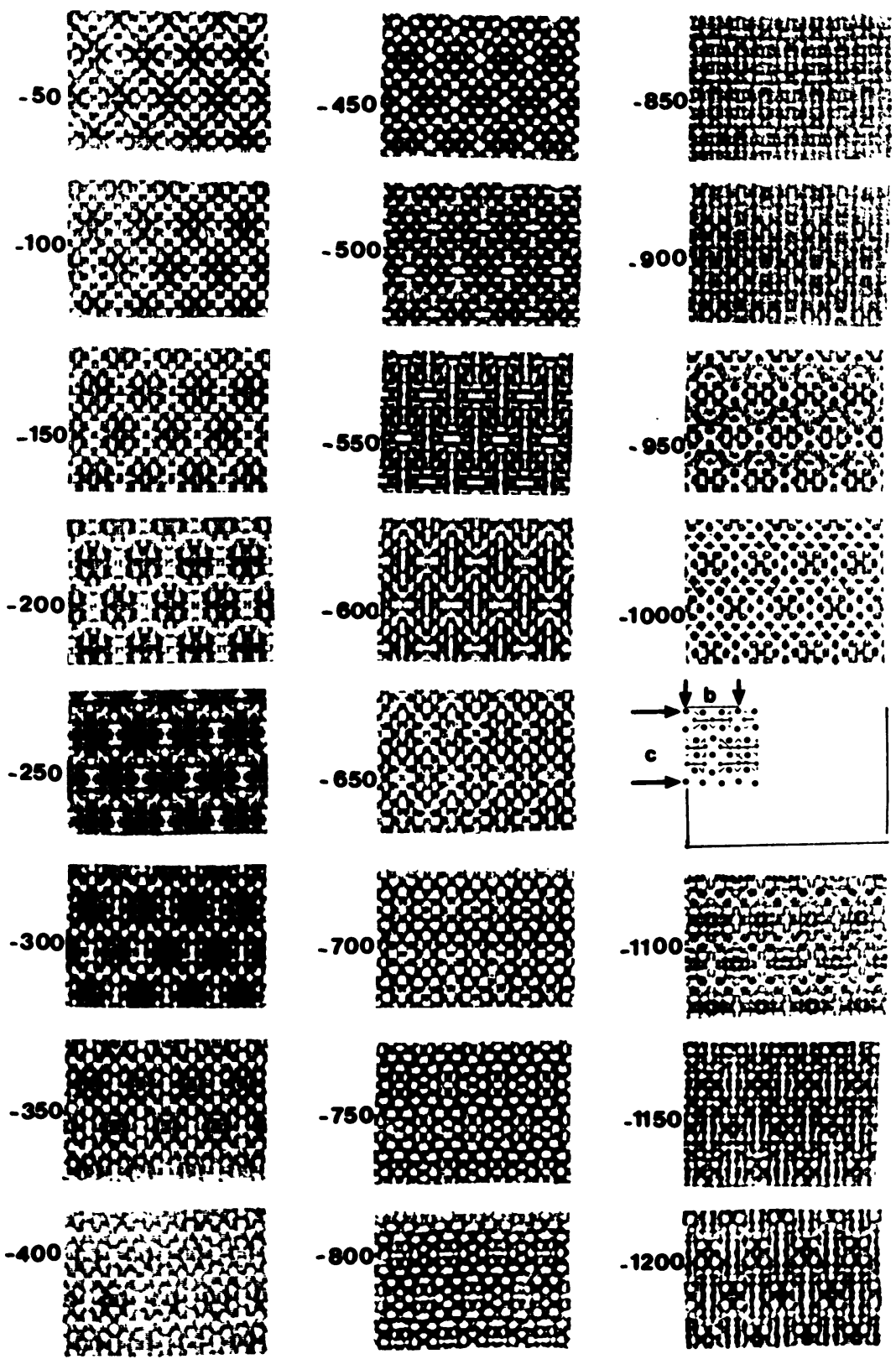

Fig. 4. - Calculated through focus series for a crystal thickness close to $30 \AA$ and [100] projected structure : the honeycomb-like contrast is observed in a large range of focus values.

Few deviations from this almost perfect ordering are observed. They can be classified in four series :

(i) oriented domains

(ii) intergrowth defects 

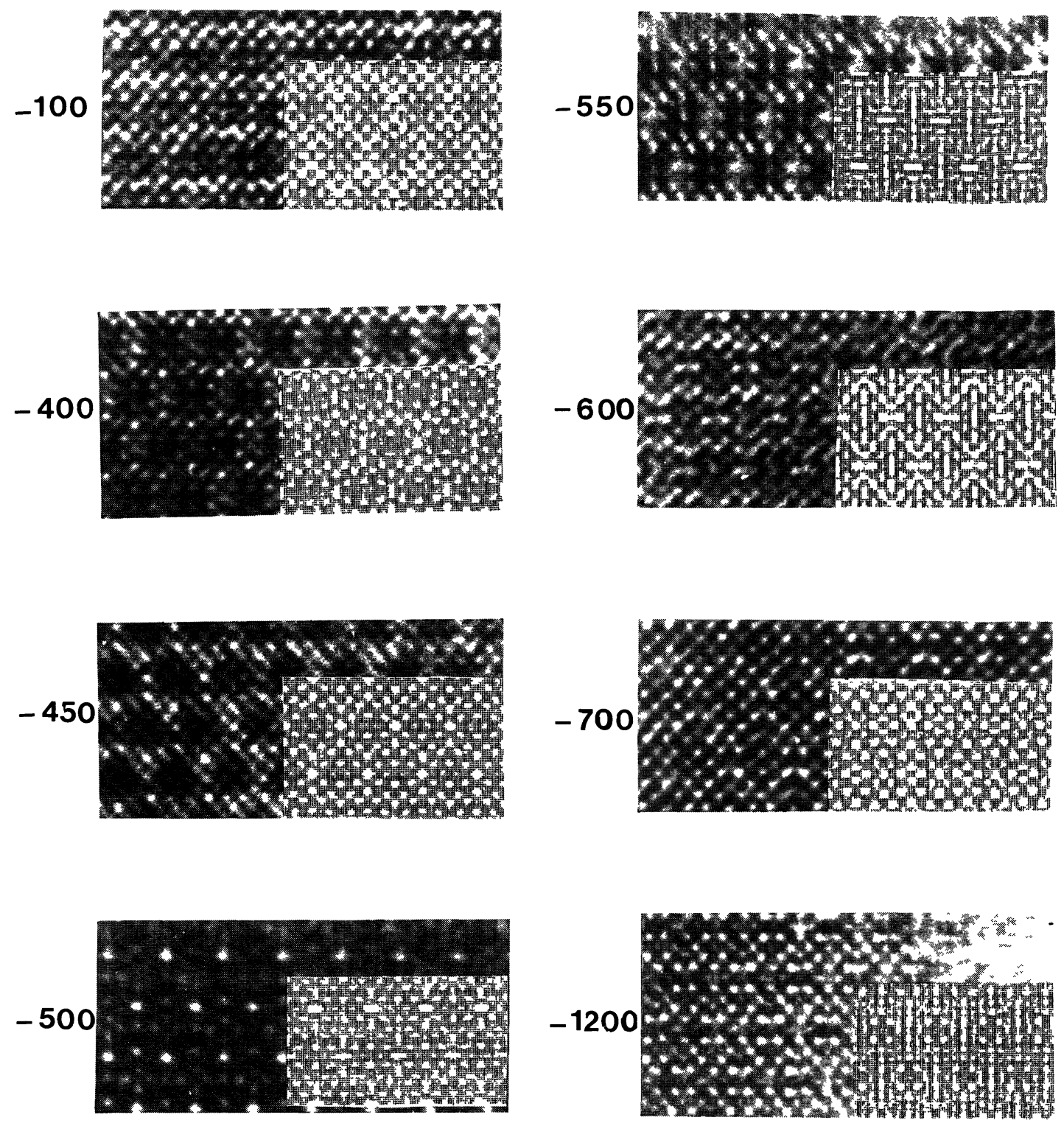

Fig. 5. - some examples of [100] experimental images compared with the corresponding calculated ones for a thickness close to $30 \AA$.

(iii) antiphase boundaries

(iv) complex disruptions

(i) Oriented domains : some crystals exhibit oriented domains whose caxes are roughly parallel. An example is shown in figure 9 where a typical [100] contrast is observed in the right part of the micrograph and a [010] contrast in the left part ; an angle of about $5^{\circ}$ is observed between the c-axis in each domains. Such phenomena are usually observed in ordered perovskites, as they correspond to the establishment of the superstructures along one or the other of the equivalent 

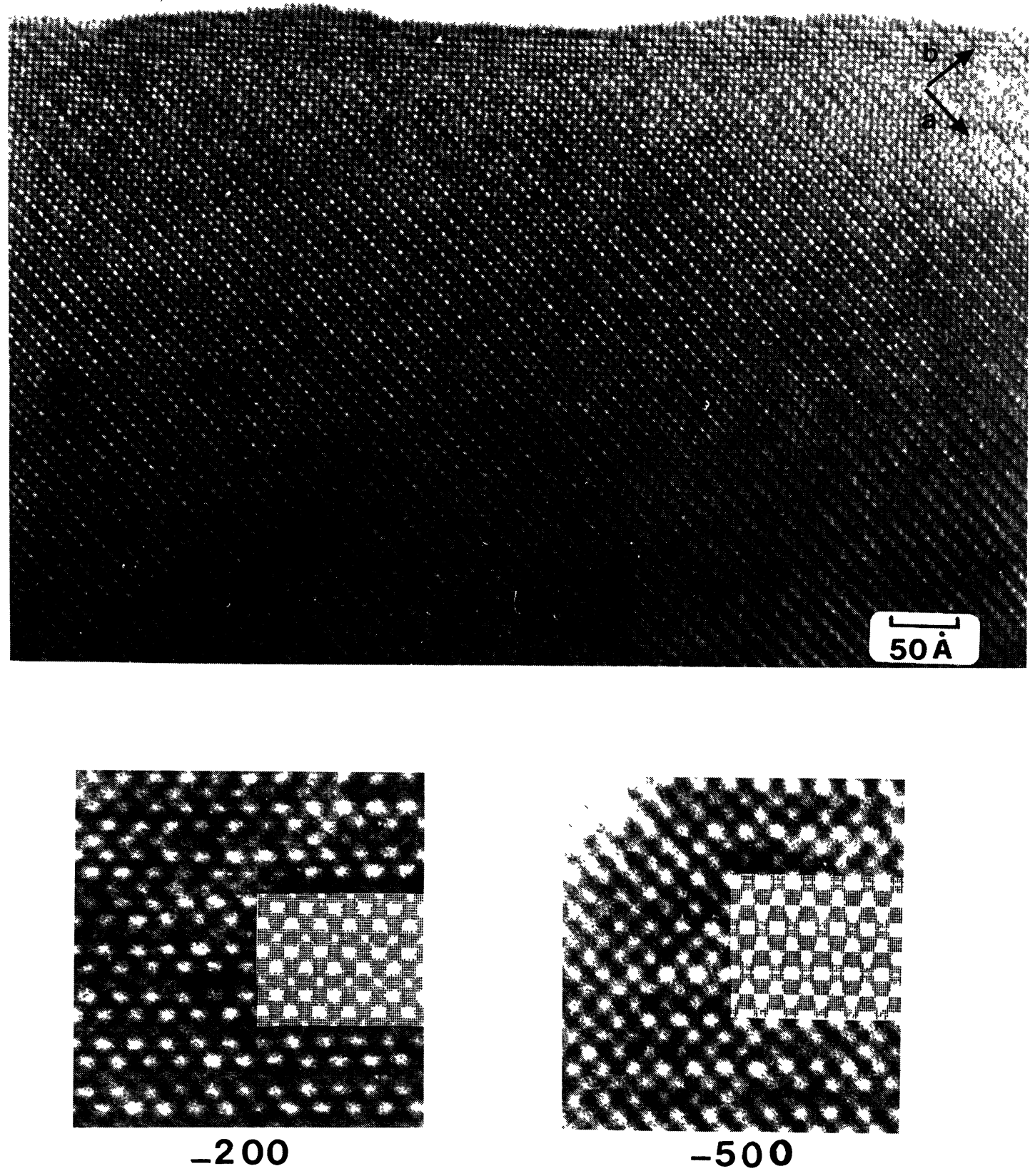

Fig. 6. - a) The contrast of the [001] images mainly consists in a network of white dots spaced of $2.8 \AA$ with a modulation along $\mathbf{b}$. Note the regular contrast of the image. b) compared experimental and calculated images for crystal thickness close to $30 \AA$ and focus values $-200 \AA$ and $-500 \AA$ respectively.

axes of the perovskite subcell (Fig. 10a). The domain boundaries can be one of the principal directions of the perovskite, mainly $[100]_{\mathrm{p}}$ or $[110]_{\mathrm{p}}$, or wander in the bulk but they generally do not affect the host lattice. On the contrary, in the neodymium phase, this type of domain is rare 


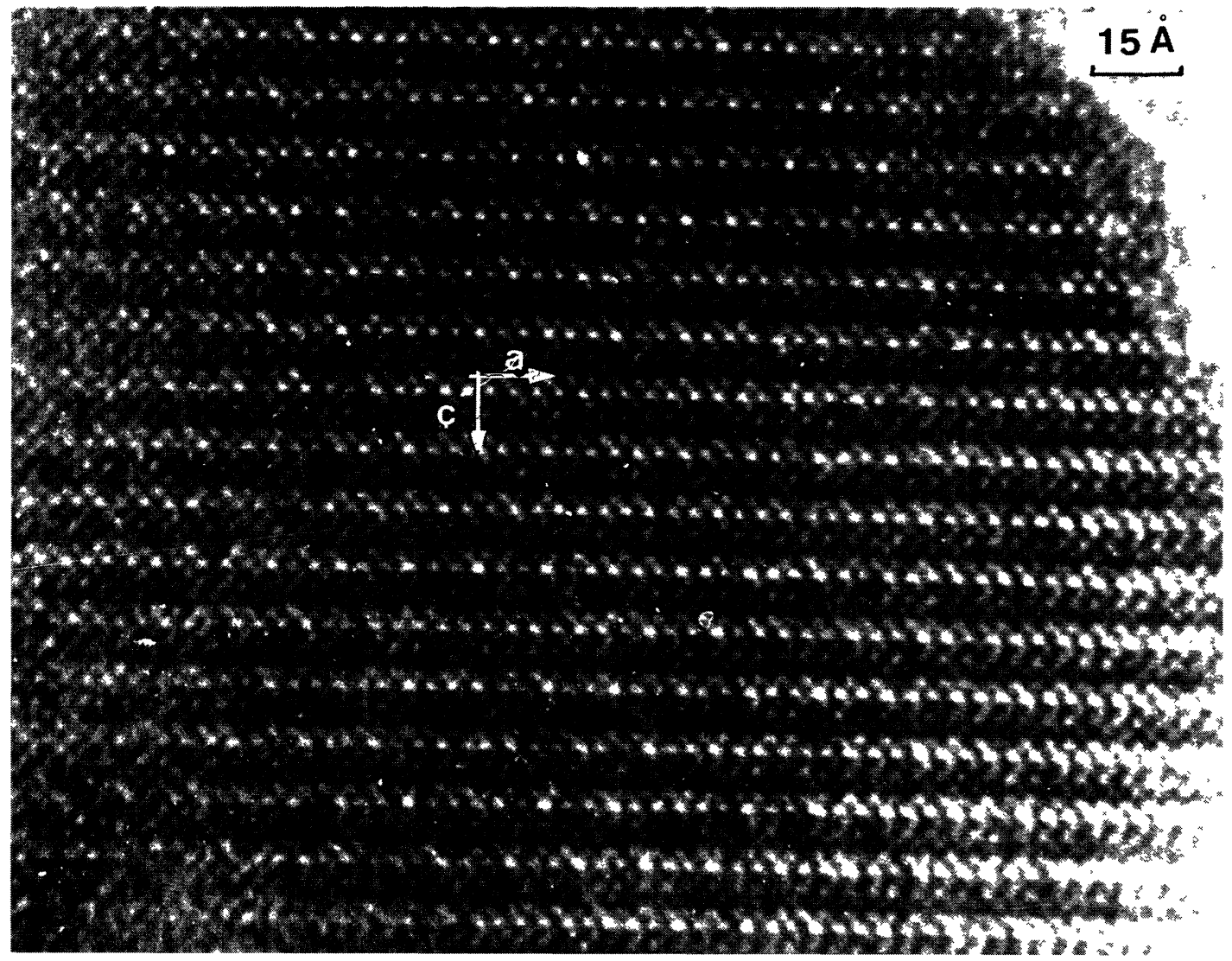

Fig. 7. - [010] images of $\mathrm{Sr}_{2} \mathrm{NdCu}_{2} \mathrm{O}_{5.76}$. The contrast is typical of a structure built up from a single rock salt layer intergrown with a double perovskite layer.

and no straight boundary is observed, moreover, the junction zone (curved arrowed) is always highly disturbed. This suggests that the domain boundary does not correspond to the classical one (Fig. 10a) but rather to the superposition of oriented areas along $\mathbf{c}$ (Fig. 10b) in a mica-like crystal.

(ii) Intergrowth defects : some intergrowth defects are observed, they all correspond to a variation in the rock salt layer thickness. This feature is especially clearly observed in the [100] images where a white strip appears in the honeycomb-like contrast (Fig. 11a). On the enlarged image of such defects (curved arrows in Fig. 11b), the phenomenon can be easily interpreted. The two [AO] layers of the single rock-salt layer $(n=1)$ appear as whiter rows (small black arrows); at the level of the defect, four layers are observed, as the translation of the two adjacent perovskite slices (labelled P); this in agreement with the existence of larger defective rock-salt layers $\left(n^{\prime}=3\right)$ as shown in figure 12. Along [010], the interpretation of the defect is more difficult to carry out. On the examples (curved arrows) showed in figure 13, the perovskite slices "P" are moved away from each other and $a / 2$ translated in the same way. Only $n^{\prime}=3$ intergrowth defects have been observed in that sample.

(iii) Low angle grain boundaries (labelled A.B.) are observed in some crystals (Fig. 14, 15). 


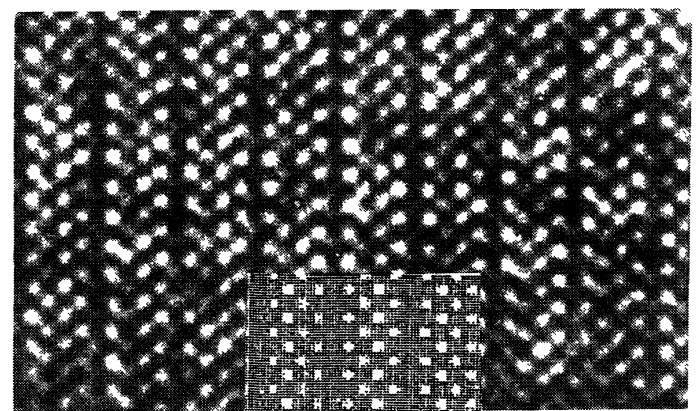

$-150$

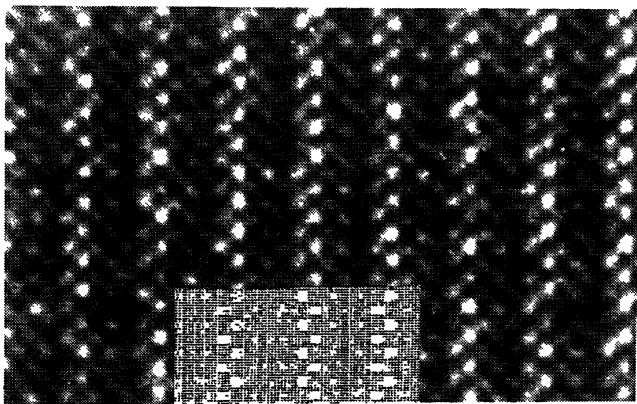

$-350$

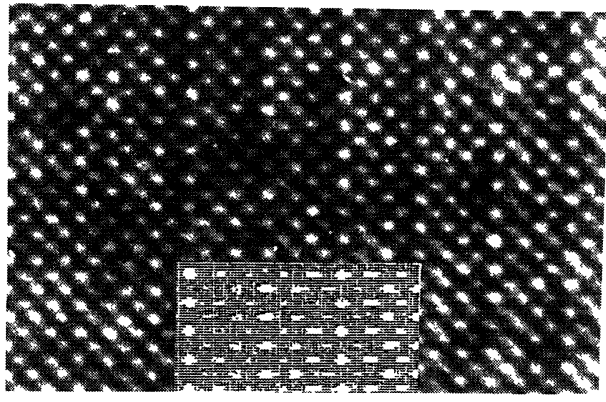

$-650$

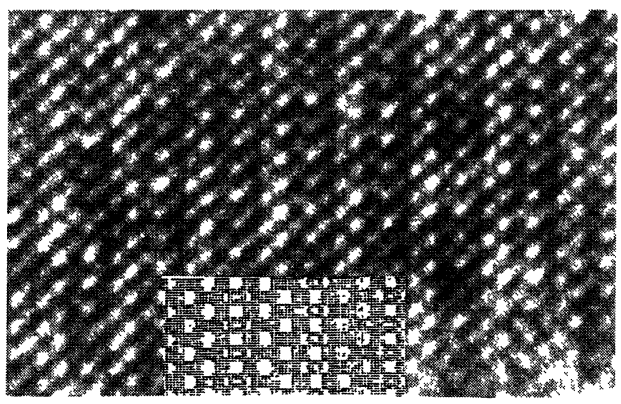

$-750$

Fig. 8. - Partial [010] through focus series : experimental and calculated images, for a thickness close to $30 \AA$, are compared.

A translation of the network is observed through the boundaries which are not straight but only roughly parallel to [100]. The striking feature is that the translation vector is not identical from one boundary to the other. For instance, in figure $14 \mathrm{a}$, we observe a translation of about $3.8 \AA$; this value and the identification of the layers (the perovskite slice "P" is white arrowed) in the sequences allow a model to be proposed (Fig. 14b). In that direction, [010], the oxygen atoms and vacancies are superimposed, so that the copper polyhedra are drawn as squares, without taking into account their real nature $\left(\mathrm{CuO}_{5}\right.$ pyramids or $\mathrm{CuO}_{4}$ groups). We observe that one row of copper $\left[\mathrm{CuO}_{2-x}\right]_{\infty}$ (black arrowed) out of two remains unchanged through the boundary whereas the other is connected to a $[\mathrm{AO}]_{\infty}$ layer.; as a consequence, the two other layers of Sr-Nd atoms cross over the boundary without change in the nature of the ions but with a change in their coordination (from rock salt-type to perovskite-type environnement). In the second example (Fig. 15a) the translation $(t \approx 2 \AA)$ is shorter so that the interconnection of the layers is different ; an idealized model of the feature, drawn with a similar symbolism for copper polyhedra, is shown on figure 15b. In that model, it can be seen that every copper layer is connected to a Sr-Nd layer and one $[\mathrm{AO}]_{\infty}$ rock-salt layer (out of two) remains unchanged through the boundary, and that the 


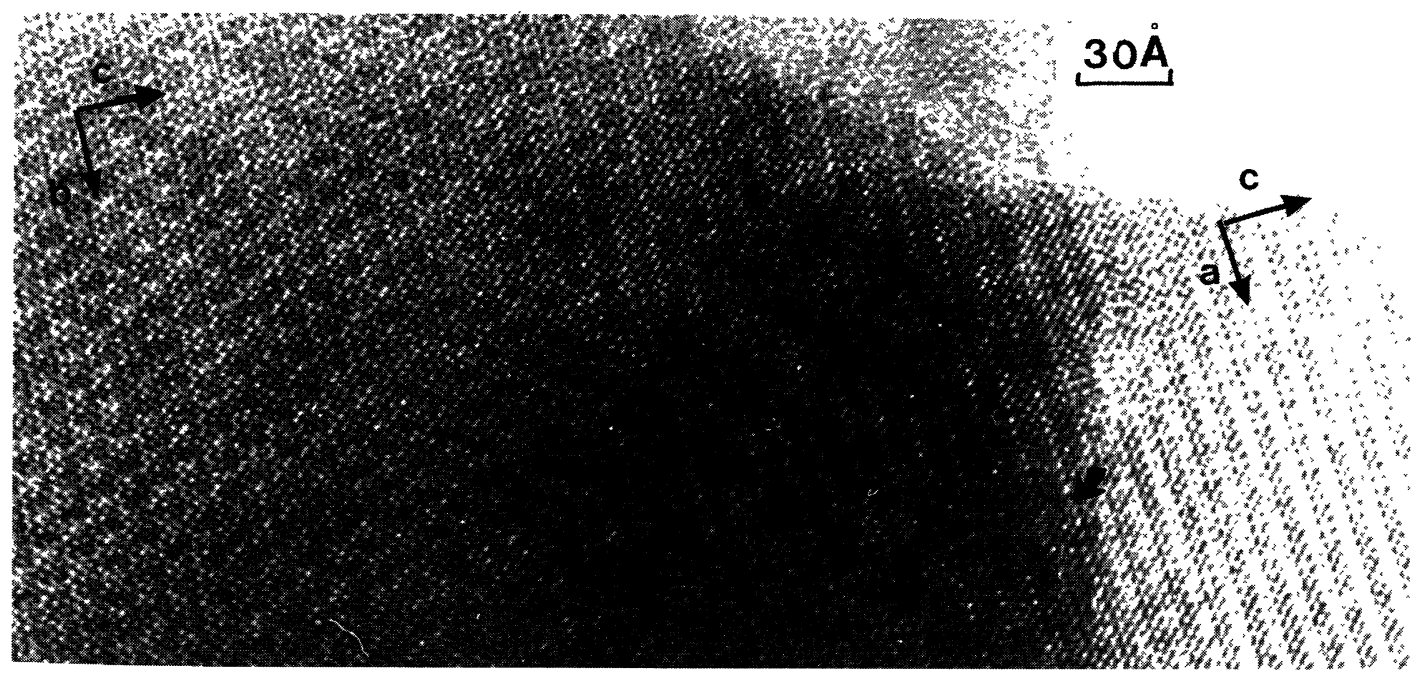

Fig. 9. - example of oriented domains. The $b=3 \times a_{p}$ superstructure set up along two orthogonal directions with a common $\mathbf{c}$ axis. The junction area (curved arrows) is large and disturbed.

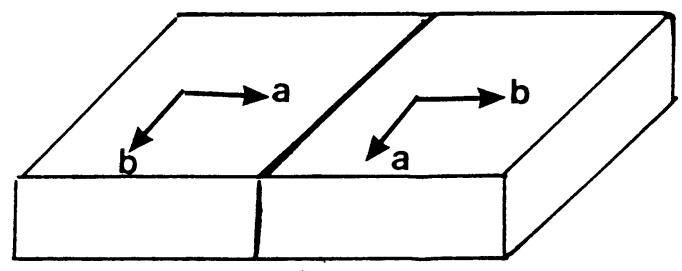

a

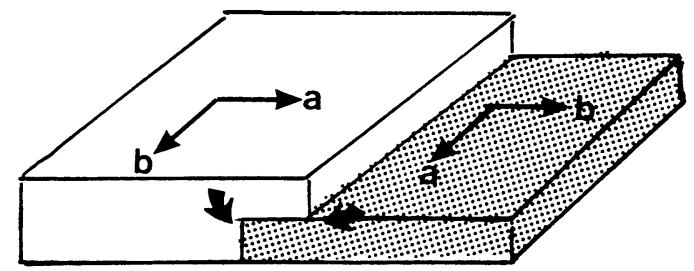

b

Fig. 10. - Schematical drawing of the $90^{\circ}$ - oriented domains. a) usual arrangement in oxygen deficient perovskite : the boundary can be straight as in that example or wanders in the bulk. b) superimposition of two $90^{\circ}$ rotated lamellae in mica-like material. The boundary is often large and disturbed as observed in figure 9.

boundary consists in a waving rock salt layer. The structural relationship between the adjacent domains are similar to those involved by antiphase boundaries; however the nature of the interface corresponds in fact to atomic arrangements, to ensure the layers interconnection, different from that of the phase, implying rather a "low angle grain boundary" heading. It should be noted that the proposed models are idealized and do not take into account the local distortions implied by the junction of layers of different natures.

Similar mechanism of layers interconnection were observed in the oxide $\mathrm{Pb}_{2-x} \mathrm{Bi}_{x} \mathrm{Sr}_{2} \mathrm{Y}_{0.5} \mathrm{Ca}_{0.5}$ $\mathrm{Cu}_{3} \mathrm{O}_{8}(8)$ which is built up from the intergrowth of single rock salt layers with one single per- 

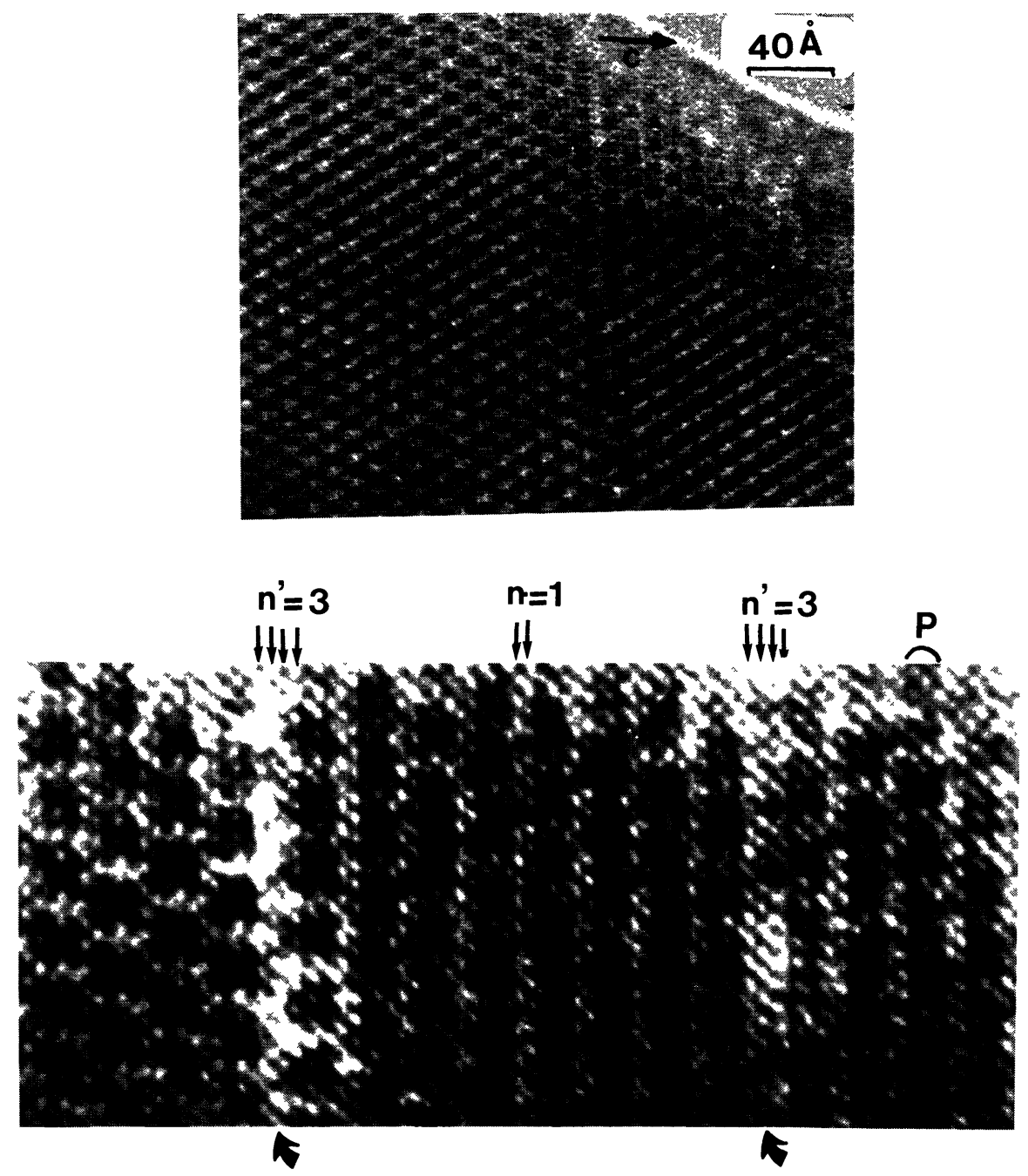

Fig. 11. - intergrowth defects : a) white strips are observed which move away from each other the perovskite slices. b) The enlarged image of such defects (curved arrows) shows that four adjacent [AO] layers (small black arrows) set up in the structure in a $n^{\prime}=3$ defective rock salt layer.

ovskite layer and one double perovskite layer, alternately. In that way, the mechanism previously proposed is not specific to the lead-bismuth oxides but appears as a more general phenomenon. In both oxides, a slight misorientation of the adjacent domains (close to $3^{\circ}$ in that example) is observed : it was correlated to the difference in thickness of the rock salt and perovskite layers which does not allow a perfect junction to be ensured.

(iv) Other local disruptions : The [001] images show that the superstructures usually established along the $\mathbf{b}$ axis are sometimes more complex, leading to the coexistence of different periodicities. In that way, modulations of the contrast are locally observed, which generally set up along [110]p or [310]p. An example is shown in figure 18, where the new periodicity is $3 \times d_{130}$. These features are supposed to be correlated with a different local ordering of the oxygen atoms and vacancies and to affect only few slices in the bulk.

Another local phenomenon must be reported, dealing with monoclinic distortions of some crys- 


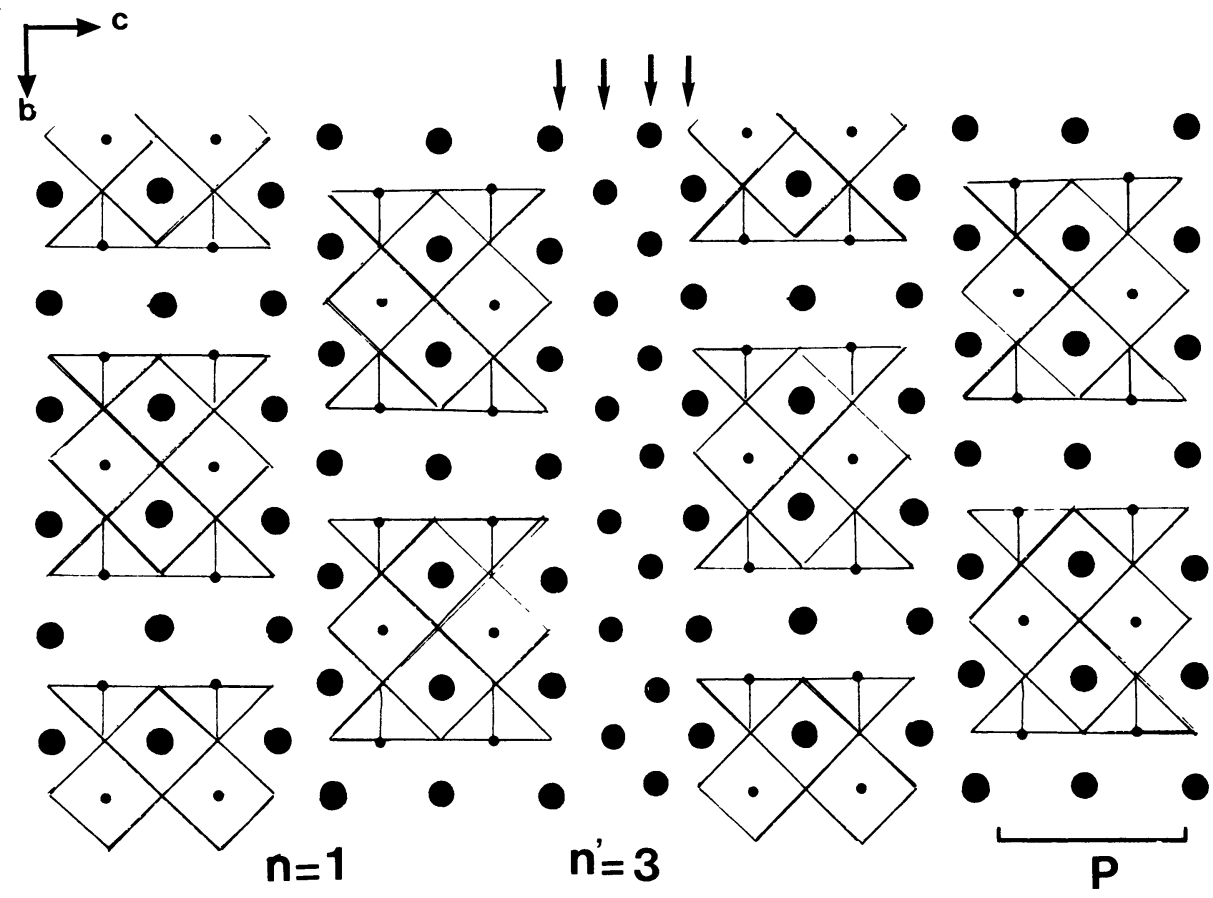

Fig. 12. - Idealized model of the $n^{\prime}=3$ defective layer built up from adjacent [ $\left.\Lambda \mathrm{O}\right]$ layers (small arrows); the perovskite slices are labelled $\mathbf{P}$.

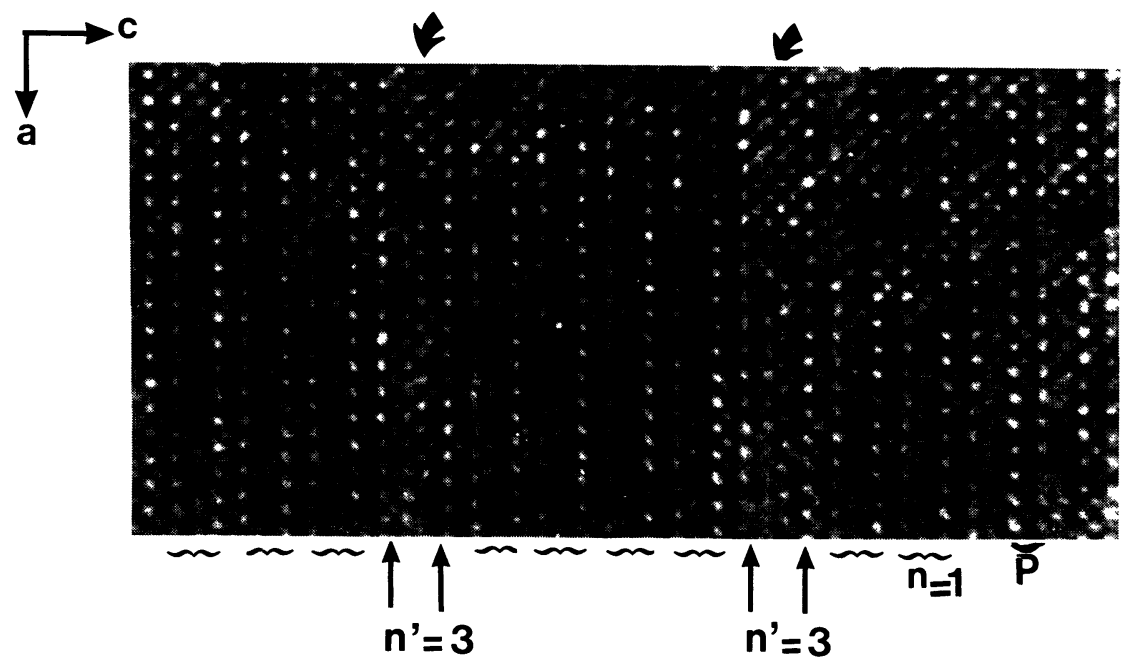

Fig. 13. - example of two $n^{\prime}=3$ defective layers viewed along [010]. The perovskite slices, P, are imaged as two rows of white spots separed by a single row of weak dots. 

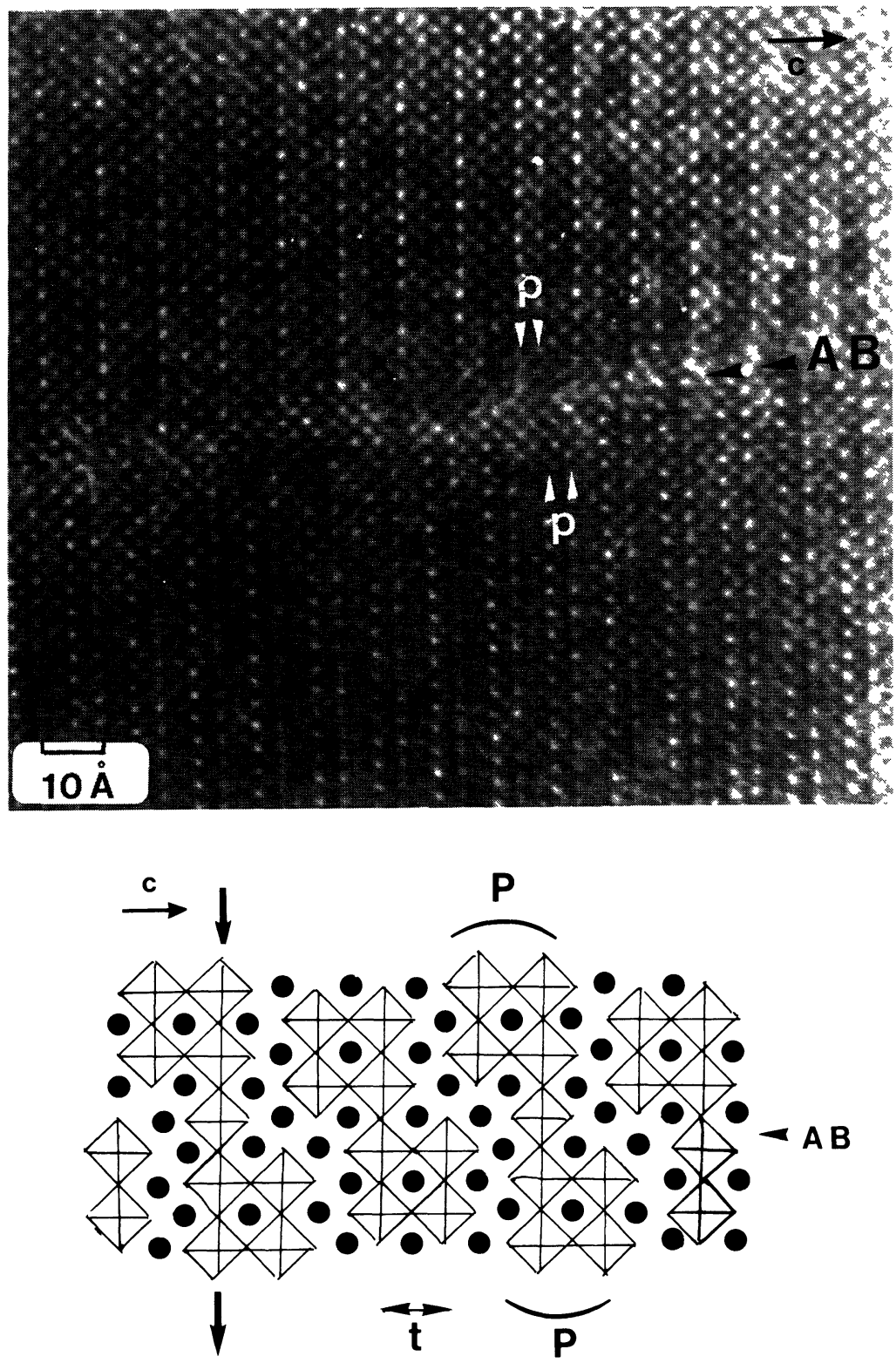

Fig. 14. - a) [010] image of an antiphase boundary (A.B) roughly parallel to (100). In that example, the networks are translated of about $3.8 \AA \sim a_{\mathrm{p}}$ as clearly observed considering the perovskite slices $\mathrm{P}$ (white arrowed). Note that the boundary area is not disturbed. $b$ ) idealized model of both domains and the boundary. In that model, one copper polyhedra layer remains unchanged through the boundary (black arrows) whereas the other is connected to a $[\mathrm{AO}]_{\infty}$ layer. The translation, $t$, of the network is close to $3.8 \AA$.

tals or some crystal areas. They are observed as well on E.D. pattern (Fig. 17) as on the HREM images but, in that case, no variation of the constrast which could be correlated with a specific ordering occurs simultaneously. The origin of such distortions is not yet understood.

Lastly, it must be noted that if the morphology of the crystals is not really a mica-like morphol- 


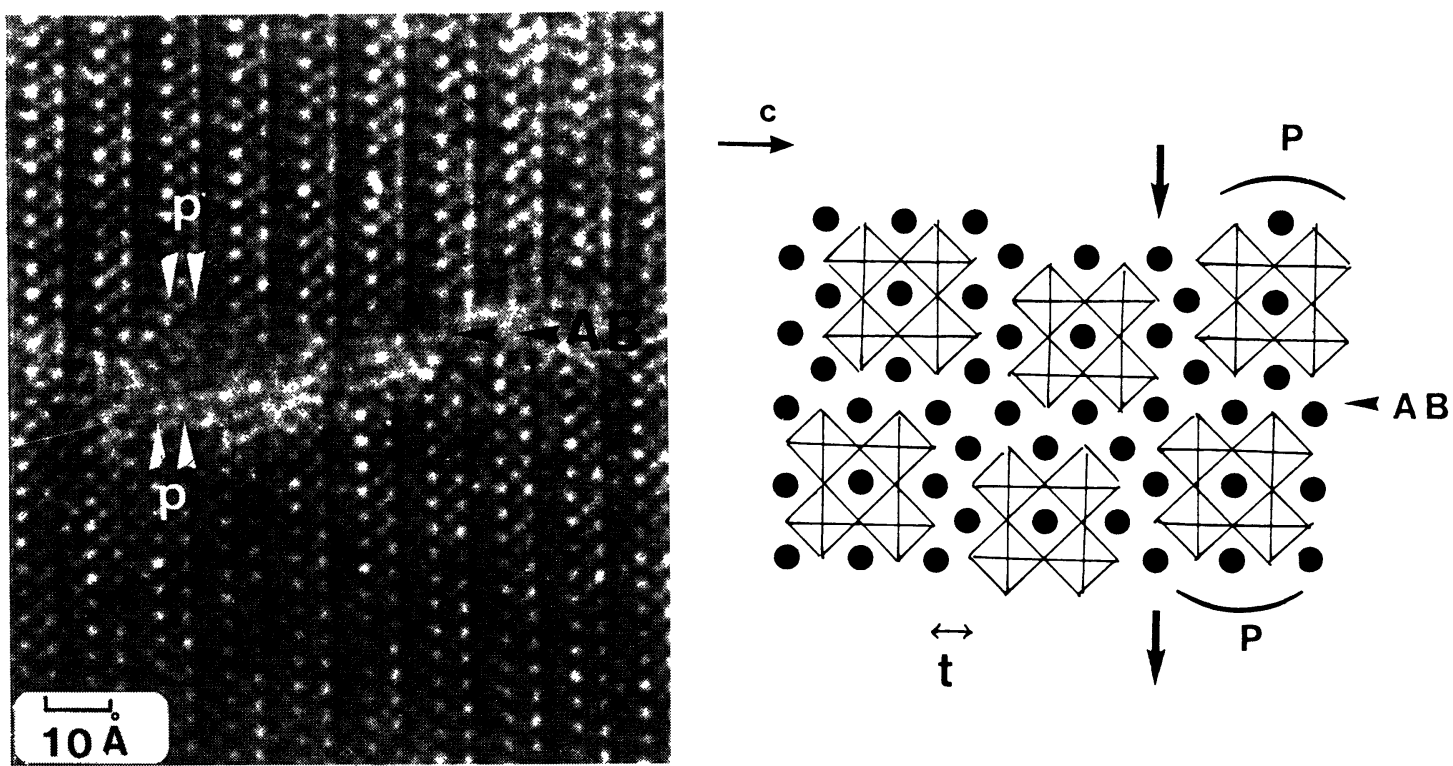

Fig. 15. - a) [010] image of an antiphase boundary where a shorter translation, $t \sim 1.9 \AA$, is observed. b) idealized model of the defect : only one $[\mathrm{AO}]_{\infty}$ layers remains unchanged through the boundary (black arrows) whereas the two $\left[\mathrm{CuO}_{2}\right]$ layers are connected to $\mathrm{Sr} \mathrm{Nd}$ layers.

ogy, we observe a real preferential cleavage parallel to (001), i.e. to the layers, which generally occurs at the level of the rock salt-type layers.

Tac influence of the $\mathrm{Ln}^{\mathrm{III}} / \mathrm{A}^{\mathrm{II}}$ ratio in the " 0212 "-type oxide, firstly reported in the lanthanum oxides [9], was confirmed by the latter studies $[5,7,10]$. The variation in the oxygen content, resulting from both cation ratio and thermal treatment, implies changes in copper coordination. In $\mathrm{Sr}_{2} \mathrm{NdCu}_{2} \mathrm{O}_{5.76}$, it appeared, from neutron diffraction results, that two types of oxygen sites are partially occupied, involving two types of coordination for $\mathrm{Cu}(1)$ : pyramidal and square planar. High resolution electron microscopy has shown that an even contrast is observed throughout the crystals, suggesting a regular distribution of the oxygen atoms and vacancies over the two sites. It has shown that few defects are in fact observed in the $\mathrm{Sr}_{2} \mathrm{NdCu}_{2} \mathrm{O}_{5.76}$ cuprate. It is interesting to note that the intergrowth defects only affect the formation of triple rock salt layers; such a feature had never been reported before in related $(\mathrm{SrO})\left(\mathrm{SrMO}_{3-x}\right)_{m}$ phases $(\mathrm{A}=\mathrm{Ti}, \mathrm{Mn}, \mathrm{Fe})$. The second interesting point of this study deals with the existence of layers interconnections : this type of mechanism was previously observed in lead oxides [8]. The formation of mixed $\mathrm{Pb}-\mathrm{Cu}$ layers could be considered liable for this nonstoichiometry feature but the occurence of similar interconnections in lead free oxides shows that it corresponds, in fact, to a more general mechanism. 


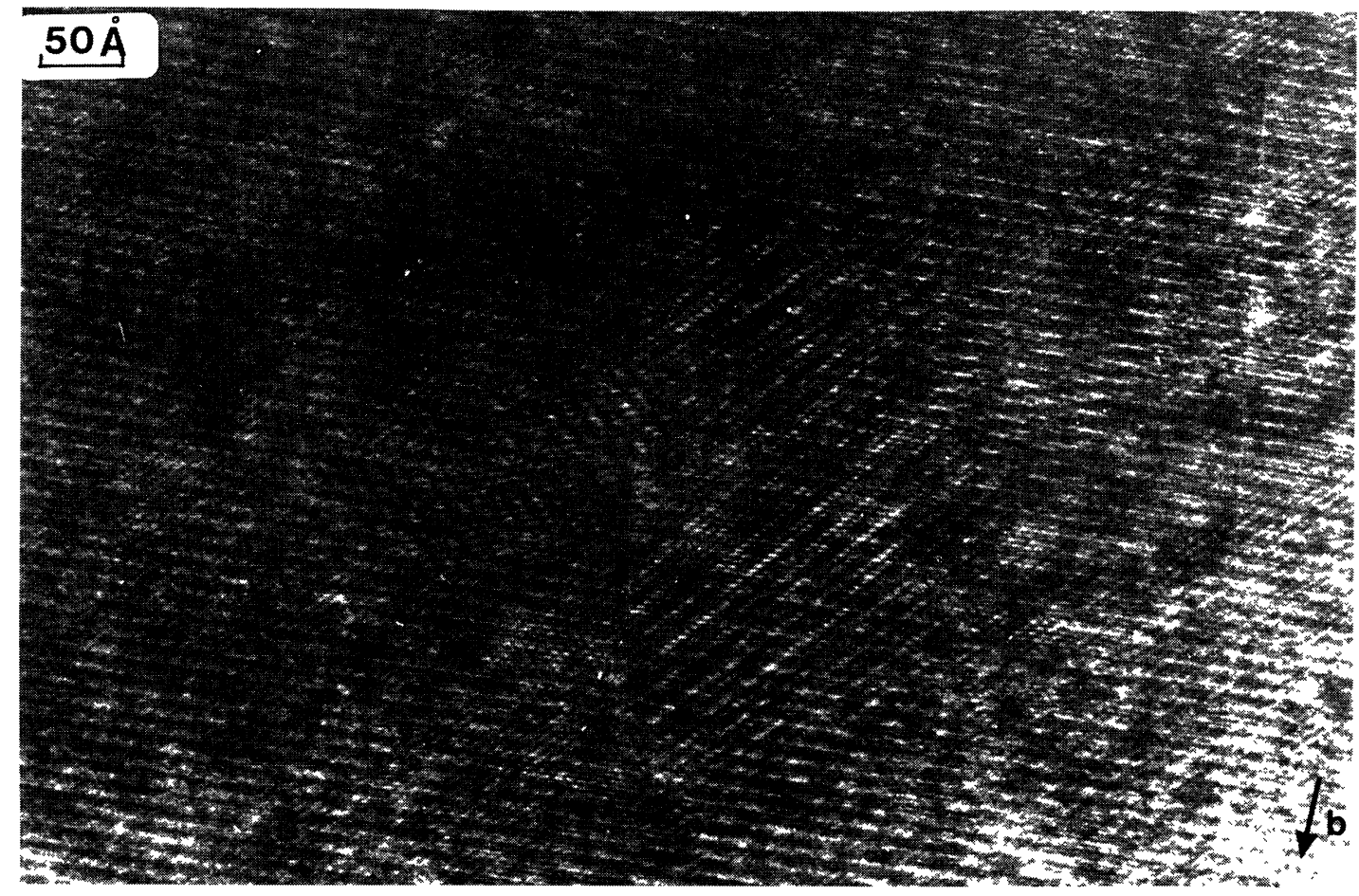

Fig. 16. - [001] image where local modulations are observed along $[110]_{p}$ and $[1 \overline{1} 0 \mathrm{p}]$, i.e. $[310]$ and $[1 \overline{3} 0]$, with a periodicity corresponding to $3 \times d_{130}$.

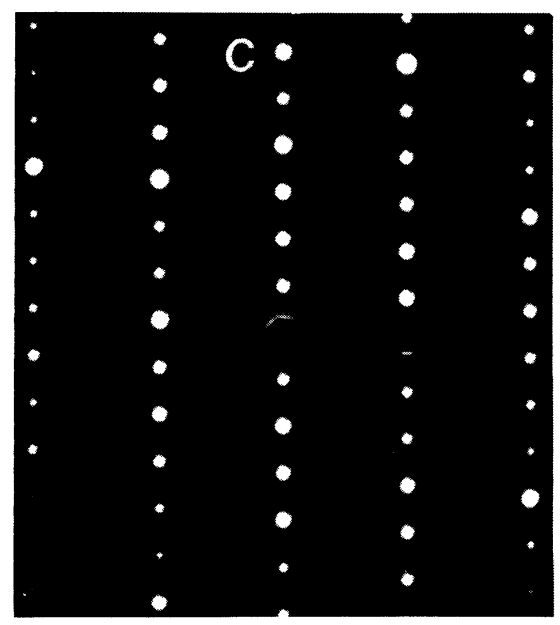

Fig. 17. - monoclinic distortions are sometimes observed in [010] E.D. patterns. 


\section{References}

[1] Raveau B., Michel C., Hervieu M., Groult D. and Provost J., Mat. Res. Soc. Symp. Proc. 156 (1989) 129.

[2] Nguyen N., ER-Rakho L., Michel C., Choisnet J. and Raveau B., Mat. Res Bull. 15 (1980) 891.

[3] Torrance J. B., Tokura Y., Nazzal A. I. and Parkin S. S. P., Phys. Rev. Lett. 60 (1988) 542.

[4] HinATANi M., SOWA T., TAKEDA Y. and MIYAUKI K., Solid State Commun. 72 (1989) 541.

[5] Caignaert V., Retoux R., Michel C., Hervieu M. and Raveau B., Physica C 167 (1990) 483.

[6] Michel C., ER-RAKHo L., Hervieu M., PANnetier J. and RAVEAU B. J. Solid State Chem. 68 (1987) 143.

[7] Caignaert V., Retoux R., Hervieu M., Michel C. and Raveau B. submitted to Physica $C$.

[8] HeRvieu M., Caignaert V., Retoux R. and RaVEaU B., Material Sci. Eng. B6 (1990) 211.

[9] NGuYen N., Choisnet J. and RaVEau B. Mat. Res. Bull. 17 (1982) 567.

[10] STeEman R. A., De Leeuw D. M., GeElen G. P. J. and FikKEe E., Physica C, 162-164 (1989) 542.

Cet article a été imprimé avec le Macro Package "Editions de Physique Avril 1990". 